\title{
Strategi Digital Content Marketing pada Akun Media Sosial Instagram Mojok.co dalam Mempertahankan Brand Engagement
}

\section{Digital Content Marketing on the Social Media Instagram Account of Mojok.co in Maintaining Brand Engagement}

\author{
Dhealda Ainun Saraswati ${ }^{1}$ dan Chatia Hastasari ${ }^{2}$ \\ ${ }^{1,2}$ Program Studi Komunikasi, Fakultas Ilmu Sosial, Universitas Negeri Yogyakarta \\ 1,2 Alamat: Jalan Colombo Yogyakarta No. 1, Karang Malang, Caturtunggal, Kecamatan \\ Depok, Kabupaten Sleman, Daerah Istimewah Yogyakarta, Indonesia 55281 \\ Email: dhealda.ainun2016@ student.uny.ac.id
}

\begin{abstract}
Abstrak
Penelitian ini untuk memahami strategi pengelolaan digital content marketing pada akun media sosial Instagram Mojok.co dalam mempertahankan brand engagement. Penelitian ini menggunakan pendekatan kualitatif deskriptif dengan teknik wawancara dan dokumentasi. Subjek penelitian ini adalah tim media sosial Mojok.co dan pengikut Instagram Mojok.co yang dipilih secara purposive. Hasil penelitian ini menjunjukan bahwa strategi digital content marketing pada akun media sosial Instagram Mojok.co terbagi dalam beberapa tahapan yaitu 1) Menetapkan Tujuan dengan membangun brand awareness Mojok.co, 2) Pemetaan Target Pasar yaitu anak muda usia 18-24 tahun atau di masa aktualisasi diri, 3) Penggagasan dan Perencanaan Konten dilakukan dengan dua format konten utama yaitu konten turunan dan konten orisinil, 4) Penciptaan Konten dilakukan oleh tim media sosial Mojok.co dalam satu minggu sekali, secara spontan dan sistem tabungan, 5) Distribusi Konten dilakukan menggunakan owned media, 6) Penguatan Konten dilakukan dengan meningkatkan kualitas, evaluasi dan inovasi pada konten, memperluas jangkauan kontributor dan menjadi pemancing isu baru, 7) Evaluasi Pemasaran Konten dilakukan dengan kurasi konten yang bersifat relateable dan shareable, 8) Perbaikan Pemasaran Konten dilakukan dengan kurasi dan inovasi konten serta mengikuti tren di media sosial.
\end{abstract}

Kata Kunci: Content Marketing, Instagram, Mojok.co, Brand Engagement

\begin{abstract}
This goal of the research is to determine the strategy for managing digital content marketing on the social media Instagram account of Mojok.co in maintaining brand engagement. This reserach used descriptive qualitative approach in the form of interview techniques and documentation. The reserach subjects were the social media team and the followers of the Mojok.co Instagram account who were selected by purposive. The results showed that the strategy of digital content marketing on the social media Instagram account of Mojok.co is divided into several stages, namely 1) Goal Setting by building brand awareness Mojok.co, 2) Audience Mapping, namely young people aged 18-24 years or in their future self-actualization, 3) Content Ideation and Planning are carried out with two main content formats, namely derivative content and original content, 4) Content Creation is carried out by the Mojok.co social media team once a week, spontaneously and using a savings system, 5) Content Distribution is carried out using owned media, 6) Content Amplification is done by improving quality, evaluation and innovation in content, expanding the reach of contributors and becoming a trigger for new issues, 7) Content Marketing Evaluation is carried out by curating content that is relateable and shareable, 8) Content Marketing Improvement is done by curating and innovating content as well as following trends in social media.
\end{abstract}

Keywords: Content Marketing, Instagram, Mojok.co, Brand Engagement 
Biokultur, 2020, 9 (2): 114-128. DOI: http://dx.doi.org/10.20473/bk.v9i2.22980.

Article History:

Received November 2, 2020; Accepted November 19, 2020; Published Online November 20, 2020

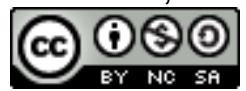

\section{Pendahuluan}

Perkembangan dunia pemasaran semakin meluas, terlebih dengan munculnya berbagai cara dalam melakukan berbagai strategi pemasaran. Saat ini, komunikasi pemasaran tidak hanya dilakukan melalui cara yang konvensional, namun ada cara lain yang digunakan, yakni penerapan content marketing (konten pemasaran). Menurut Kotler, Kartajaya, dan Setiawan (2017: 121), content marketing adalah pendekatan pemasaran yang melibatkan pembuatan, kurasi, distribusi, dan dapat memperkuat konten tersebut menjadi menarik, relevan, serta bermanfaat bagi kelompok spesifik agar menciptakan pembahasan mengenai konten.

Prinsip content marketing adalah menawarkan konten di media cetak maupun media digital, yang relevan dengan target pasar. Konsekuensinya, konten harus didesain secara khusus sesuai kebutuhan target market. Situasi ini kemudian memunculkan fenomena "media rent to media own" (Pandrianto dan Sukendro 2018: 169). Content marketing dalam hal ini memiliki arti sebagai kegiatan pemasaran yang menyajikan konten sebagai hal yang utama dalam melakukan branding ataupun memasarkan produk.

Berdasarkan data penilaian di sektor B2B (business-to-business) terkait efektivitas penerapan serta penggunaan content market-ing di tahun 2014, menilai content marketing dianggap efektif hingga sangat efektif sebanyak $42 \%$ (academy.getcraft.com 2020). Hal ini dapat terlihat dari keragaman konten yang digunakan dalam melakukan branding, serta efisiensi biaya serta waktu dari kegiatan pengelolaan content marketing.

Kesalahpahaman makna content marketing yang hanya sebagai promosi dan penjualan dapat dipertimbangkan oleh para pebisnis agar kegiatan pemasaran juga bermanfaat bagi pelanggan. Chakti (2019: 126) memaparkan bahwa daripada hanya melempar produk atau layanan, lebih baik memberikan konten yang benar-benar relevan dan bermanfaat bagi prospek dan pelanggan untuk membantu mereka memecahkan masalah. Menurut Sanawiri dan Iqbal (2018: 134), content marketing bukan hanya sekadar post biasa, tapi didesain khusus untuk berinteraksi, berhubungan, dan memberi kesan kepada pengguna untuk mengetahui lebih dalam mengenai suatu hal.

Salah satu wadah ataupun tempat pengelolaan content marketing yaitu media sosial. Kotler dkk (2017: 122) menjelaskan bahwa media sosial telah memainkan peran utama dalam perubahan dunia pemasaran. Di masa lalu, pelanggan mendengarkan dengan seksama konten yang disiarkan secara tradisional di media, termasuk iklan. Mereka tidak punya pilihan. Media sosial mengubah semua itu. Saat ini, pelanggan mempunyai konten yang dihasilkan pengguna dalam jumlah besar yang lebih kredibel dan menarik dari media tradisional. Hal yang membuat konten di media sosial terlihat menarik adalah pelanggan bersifat sukarela dalam mengakses sesuai kemauan, yang 
berarti pelanggan memilih untuk mengonsumsi konten kapan saja dan di manapun mereka menginginkannya.

Media sosial sebagai salah satu alat dalam pengelolaan content marketing juga memiliki tujuan untuk mendekatkan bahkan hingga melibatkan pelanggan untuk mengikuti brand atau sebuah perusahaan. Hal ini disebut dengan brand engagement. Brand engagement menjadi hal yang penting saat ini, terlebih dengan adanya pemasaran yang dilakukan secara online oleh berbagai pemasar, brand, maupun perusahaan.

Ketika sebuah brand baru memasarkan produknya, tentu memiliki strategi pemasaran yang dipersiapkan sebelumnya, berlanjut hingga produk dipasarkan, dapat dijangkau oleh khalayak dan pada akhirnya sebuah brand akan mempunyai target pasar tersendiri atau pun pelanggan setianya. Target pasar atau pelanggan setia yang dimiliki sebuah brand ini yang perlu dievaluasi perkembangannya, apakah pelanggan menyukai sebuah produk ataupun bagaimana cara mempertahankan pelanggan agar tetap setia dan sangat mendukung sebuah brand, inilah di mana brand engagement (keterlibatan merek) menjadi salah satu hal yang dapat dipertimbangkan oleh pemasar atau brand.

Menurut Kapoor (2011: 131), engagement dianggap sebagai sinonim untuk komitmen dan kewajiban, engagement tampaknya memiliki konotasi positif, mengekspresikan kesenangan dan kegembiraan, bukan hanya melakukan tugas atau dedikasi. Buckingham (2008: 5) menjelaskan bahwa jawaban untuk brand management yang efektif tidak selalu dengan desain yang lebih baik, hal ini terletak pada brand engagement yang otentik dan kunci brand engagement yakni terletak pada aktivitas yang mampu mendorong kebebasan yang bertanggung jawab dan mendorong kita melakukan hal itu secara terbiasa.

Salah satu media online di Indonesia yang memiliki brand engagement dengan para pelanggannya di media sosial Instagram adalah Mojok.co. Mojok.co adalah media alternatif yang mewadahi tulisan para penulis yang punya energi serta kreativitas berlebih. Konten segar dan menghibur adalah cara bersenang-senang dan bergembira (mojok.co 2019).

Konten-konten visual yang ada pada media sosial Instagram @ mojokdotco memiliki ciri khas tersendiri yang membedakan dengan media online lainnya. Satu hal yang menjadikan konten Mojok.co memiliki ciri khas tersendiri adalah adanya unsur satire namun dibawa dengan nuansa humoris ala Mojok.co. Konten bernada satire pada akun Instagram ini juga merepresentasikan berbagai tulisan dalam artikel di situs Mojok.co.

Brand engagement Mojok.co yakni sebagai sebuah media yang fokus untuk menyasar pembaca muda berusia 18-24 tahun, Mojok menggunakan strategi pendekatan brand engagement berbasis milenial. Beberapa strategi yang diambil misalnya adalah memperkaya konten visual baik gambar dan video yang selama ini memang dikenal cukup ampuh untuk menarik minat anak muda, juga aktivasi diseminasi Instagram dan Line yang mana merupakan dua media sosial yang saat ini paling banyak digunakan oleh generasi milenial (gardamaya.com 2019). 


\section{Metode}

Penelitian ini menggunakan pendekatan kualitatif deskriptif. Penelitian dilaksanakan sekitar tujuh bulan yaitu pada bulan Januari 2020-Juli 2020. Subjek penelitian ini adalah tim media sosial Mojok.co dan pengikut Instagram Mojok.co menggunakan teknik purposive. Sumber data yang digunakan pada penelitian ini diperoleh dari data primer dengan teknik purposive yaitu wawancara dengan tim media sosial Mojok.co dan pengikut Instagram Mojok.co dan data sekunder yang diperoleh berupa data online seperti hasil screenshot dari website yang berkaitan dengan content marketing, media sosial, brand engagement serta konten-konten yang ada pada Instagram Mojok.co.

Teknik analisis data yang digunakan dalam penelitian ini adalah pendekatan kualitatif deskriptif dengan metode analisis data yang diperkenalkan oleh Matthew B.Miles dan Michael Huberman dalam Djamal (2017: 145-149) yang memaparkan bahwa kegiatan analisis data kualitatif secara interaktif dan berlangsung secara terus menerus hingga datanya mencapai titik jenuh. Analisis data ini terdiri atas reduksi data, penyajian data serta pengambilan keputusan.

\section{Hasil dan Pembahasan}

\section{Strategi Digital Content Marketing pada Akun Media Sosial Instagram Mojok.co dalam Mempertahankan Brand Engagement}

Mojok.co memiliki strategi digital content marketing yang dimulai dengan adanya komunikasi pemasaran dan digital marketing yang dilakukan terlebih dahulu. Mojok.co merupakan media opini dalam bentuk online yang melakukan berbagai kegiatan komunikasi secara online pula.

Komunikasi pemasaran yang dilakukan oleh Mojok.co mengarah kepada penyebaran informasi atau biasa disebut dengan diseminasi konten serta pembentukan citra atau branding. Kegiatan komunikasi pemasaran dilakukan oleh tim media sosial Mojok.co, mulai dari admin, ilustrator dan tim media sosial lainnya. Komunikasi pemasaran yang dilakukan oleh Mojok.co sesuai dengan Prasetyo, dkk (2018: 18) yang memaparkan bahwa komunikasi pemasaran merupakan salah satu aktivitas yang dilakukan oleh organisasi (privat maupun publik) dalam memengaruhi, memersuasi, dan mengingatkan stakeholder (konsumen atau publik) secara langsung maupun tidak langsung mengenai produk (barang dan jasa) yang dibuat oleh organisasi itu.

Prasetyo dkk (2018: 18) mengemukakan bahwa komunikasi pemasaran adalah salah satu momentum yang dilakukan oleh organisasi untuk berinteraksi dengan publik atau pelanggannya. Admin media sosial Mojok.co bertugas untuk mengunggah konten yang ada di feeds Instagram serta Instagram Story serta berkomunikasi (menanggapi direct messages dan kolom komentar Instagram) dengan pengikut akun Instagram Mojok.co. Ilustrator Mojok.co bertugas untuk memvisualisasikan pesan dalam brief konten yang diberikan oleh admin media sosial untuk dijadikan sebuah konten berbentuk ilustrasi. 
Lalu tim media sosial lainnya seperti videografer juga bertugas untuk melakukan perencanaan dan ide-ide konten lainnya seperti konten video yang ada di fitur Instagram TV (IG TV) Mojok.co.

Kegiatan digital marketing yang dilakukan Mojok.co di Instagram yaitu adanya diseminasi konten yang dilakukan oleh Mojok.co yang mendorong terciptanya hasil, yaitu berpengaruh pada jumlah page views artikel di website Mojok.co, dan tentunya akan meningkatkan traffic web Mojok.co. Selain itu, kegiatan digital marketing Mojok.co lainnya adalah membuat konten advertorial permintaan klien, seperti konten Infografik, Komik Mojok, serta Multiple Post yang biasanya berbentuk hard selling dan soft selling. Kegiatan digital content marketing yang dilakukan Mojok.co juga sesuai dengan Kotler, dkk (2017: 53) yang menjelaskan bahwa peran terpenting dari digital marketing adalah mendorong tindakan dan penganjuran. Digital marketing lebih akuntabel daripada pemasaran tradisional, fokusnya adalah mendorong tercapainya hasil, sementara pemasaran tradisional adalah memprakarsai interaksi pelanggan.

Mojok.co memiliki strategi content marketing secara umum yaitu dengan membuat konten yang dapat memancing engagement dan jangkauan (reach) serta mempertimbangkan konten yang sesuai dengan audiens akun Instagram Mojok.co. Hal lain yang perlu diperhatikan dalam melakukan strategi content marketing adalah pembuatan konten oleh ilustrator. Pembuatan konten Mojok.co mempertimbangkan tiga aspek, yaitu 1) melakukan modifikasi terhadap tokoh atau fenomena yang ikonik, lalu 2) simplifikasi konten yang berarti konten dibuat sederhana namun mengena serta 3) kesan personal pada konten yang membedakan Mojok.co dengan media lainnya karena dibuat sendiri oleh ilustrator Mojok.co. Mojok.co melakukan beberapa langkah dan tahapan dalam melakukan content marketing serupa dengan Kotler, dkk (2017: 125-134) yaitu:

\section{Menetapkan Tujuan (Goal Setting)}

Mojok.co memiliki tujuan utama dalam melakukan pengelolaan content marketing di Instagram yaitu tujuan terkait brand, lebih khususnya lagi adalah membangun brand awareness Mojok.co. Namun seiring berjalannya waktu, tujuan melakukan branding di Instagram memiliki dampak positif lain yang didapat oleh Mojok.co, yaitu penambahan pada page views website Mojok.co. Tujuan terkait brand Mojok.co sesuai dengan pernyataan Setiawan dan Savitry (2016: 66) yang menerangkan bahwa secara garis besar, tujuan content marketing dapat diklasifikasikan menjadi dua hal. Pertama, penjualan. Kedua, tujuan terkait merek (brand). Hal ini terdiri atas meningkatkan brand awareness, brand association, memperkuat brand loyalty, hingga melahirkan advokasi di antara konsumen.

Selain itu, dalam melakukan branding, Mojok.co juga terus melakukan variasi konten agar tetap konsisten. Upaya dalam melakukan variasi konten ini dapat memperluas jangkauan audiens, sehingga dapat menambah traffic web dan menjadi pertimbangan klien atau brand lain untuk mengiklankan produk di Mojok.co. 


\section{Pemetaan Target Pasar (Audience Mapping)}

Hal ini sesuai dengan target pasar Mojok.co dalam semua platform-nya yaitu anak muda berusia 18-24 tahun. Anak muda yang dimaksud juga dapat dikatakan sebagai seseorang yang sedang mencari aktualisasi diri di quarter life crisis atau sedang di tahap mencari jati diri. Dalam hal demografi seperti pendidikan, pekerjaan dan penghasilan tidak terlalu dipermasalahkan oleh Mojok.co. Pengikut akun Instagram Mojok.co juga paling banyak diikuti oleh para pria, serta domisili para pengikut Mojok.co paling tinggi di Jakarta dan urutan kedua di Yogyakarta. Pihak Mojok.co berupaya untuk terus meningkatkan pembaca wanita, agar porsi pembaca lebih seimbang.

Beberapa keresahan muncul ketika ada konten yang memicu perdebatan dan Mojok.co pun tidak memihak begitu saja. Misalnya konten yang dibuat Mojok.co berkaitan dengan fenomena Pro Nikah Muda, namun tidak menutup kemungkinan konten Mojok.co selanjutnya berkaitan dengan pihak yang Kontra Nikah Muda. Keresahan yang muncul dalam penciptaan konten lainnya berkaitan dengan isu-isu terkini. Keinginan lain dari para pengikut Instagram Mojok.co adalah dorongan untuk tampil di media sosial, sehingga Mojok.co sering mengambil isu tersebut.

\section{Penggagasan dan Perencanaan Konten (Content Ideation and Planning)}

Mojok.co memiliki format konten tersendiri pada akun Instagram. Saat ini, konten utama yang ada pada Instagram Mojok.co bernama konten turunan dan konten orisinil sebagai content marketing-nya. Kedua jenis konten ini diunggah secara reguler. Konten turunan adalah konten yang memiliki tampilan hasil screenshot judul artikel di website Mojok.co, contohnya \#HeadlineTerminal dan \#HeadlineMojok, sedangkan konten orisinil adalah konten-konten Mojok.co yang dibuat khusus untuk akun Instagram Mojok.co, contoh konten orisinil yang sedang aktif adalah \#Mojokomendasi (Bacaan, Kuliner, Bebunyian, Tongkrongan dan Tontonan), \#KomikMojok serta \#Printilan. Sebelumnya, Mojok.co memiliki konten orisinil lainnya yang pernah ada yaitu \#PanArt, \#TebakanMojok dan \#PantunMojok serta masih banyak lagi yang diganti karena adanya evaluasi.

Ada pula konten video di fitur Instagram TV (IG TV) Mojok.co yang pernah dibuat beberapa waktu lalu. Konten-konten Mojok.co dievaluasi secara berkala, sehingga terdapat beberapa konten yang tidak ditayangkan secara reguler kembali. Pembuatan caption pada setiap postingan konten menyesuaikan dengan konten yang disebarkan (diseminasi), sehingga konten bersifat fleksibel.

Dalam hal ini, konten orisinil Mojok.co merupakan konten yang memiliki tema dari realisasi slogan Mojok.co yaitu "Sedikit Nakal Banyak Akal". Konten orisinil juga sering diangkat dari fenomena seputar pro-kontra, kisah asmara, kehidupan sehari-hari masyarakat, hal-hal sepele namun tidak terduga dan sebagainya. Misalnya konten \#Printilan edisi Starter Pack yang biasanya mendeskripsikan satu tokoh yang ikonik, mulai dari pakaian hingga gaya khas yang digunakannya.

\section{Penciptaan Konten (Content Creation)}

Penciptaan content marketing Instagram dilakukan oleh kru Mojok.co sendiri yaitu admin media sosial, ilustrator dan tim media sosial lainnya seperti videografer. Penciptaan konten dimulai dari admin media sosial yang membuat brief konten terlebih dahulu lalu 
dapat diakses oleh ilustrator yang nantinya akan divisualisasikan sebagai ilustrasi konten Mojok.co. Selanjutnya, waktu dalam penciptaan konten Mojok.co terbagi dalam beberapa bagian, yaitu 1) biasanya dilakukan di hari Senin, 2) dilakukan satu kali untuk diseminasi konten dalam satu minggu lalu dieksekusi di hari penayangan, 3) dilakukan secara spontan di hari penayangan dan 4) dilakukan dengan sistem tabungan yaitu dilakukan satu minggu sebelum hari libur panjang atau hari-hari besar.

\section{Distribusi Konten (Content Distribution)}

Fokus utama dalam pendistribusian konten-konten Mojok.co adalah media yang dimiliki sendiri oleh Mojok.co, di mana akun Instagram Mojok.co dikelola oleh Mojok.co sendiri dan sepenuhnya digunakan untuk diseminasi konten. Mojok.co juga pernah menggunakan paid media ketika Instagram Mojok.co membagikan konten berbayar atau sponsor iklan dari klien, serta menggunakan earned media untuk membangun brand sehingga dapat menjangkau audiens. Sebagaimana menurut Kotler, dkk (2017: 131) bahwa owned media (media yang dimiliki) terdiri atas aset saluran yang dimiliki merek dan berada di bawah kendali sepenuhnya, dan dapat didistribusikan kapanpun.

\section{Penguatan Konten (Content Amplification)}

Dalam melakukan penguatan konten, Mojok.co melakukan berbagai upaya yaitu terus meningkatkan kualitas konten namun tetap memiliki ciri khas Mojok.co, lebih memperluas jangkauan kontributor serta menjadi pemancing isu-isu baru. Tidak hanya itu, Mojok.co juga terus melakukan evaluasi terhadap content marketing yang dilakukan, serta mencoba format-format baru pada konten.

Hal yang dilakukan Mojok.co dalam melakukan penguatan konten yang berhubungan dengan para pengikut Instagram Mojok.co, yaitu adanya interaksi antara admin media sosial dengan pengikut yaitu menanggapi dengan cepat pesan-pesan yang ada pada direct messages (DM) Instagram Mojok.co, terlebih jika terkait konten, hal-hal terkait operasional website Mojok.co seperti tuntutan untuk menurunkan artikel.

\section{Evaluasi Pemasaran Konten (Content Marketing Evaluation)}

Mojok.co melakukan evaluasi content marketing dengan berbagai cara, yaitu mulai dari melakukan kurasi terhadap konten-konten yang paling diminati oleh para pengikutnya dan berpengaruh pada kebutuhan traffic web Mojok.co. Konten Mojok.co juga dievaluasi dari berapa banyak jumlah like dan engagement dalam sebuah konten. Metrik pemasaran yang digunakan Mojok.co saat ini lebih mengarah pada konten yang bersifat relateable dan shareable. Metrik pemasaran yang bersifat visible, searchable dan actionable juga sudah dipenuhi oleh Mojok.co dalam kontennya. Mojok.co mempertimbangkan konten yang bersifat relateable dan shareable.

Senada dengan Setiawan dan Savitry (2016: 73) bahwa metrik relatability adalah pengukuran seberapa baik content marketing yang dihasilkan dapat menarik para audiens, serta metrik share bertujuan untuk mengetahui seberapa banyak audiens yang mau membagi content marketing kepada orang lain. Metrik yang digunakan pada metrik share antara lain rasio antara jumlah share dan impresi (share ratio) dan perbandingan antara jumlah pengikut pemasar di sebuah media sosial atau tingkat keterlibatan (engagement 
rate) serta berapa jumlah yang menjadikan retweets, favorites, replies, atau mentions pada akun media sosial.

Selain itu, Mojok.co juga mengevaluasi konten dari data analytic yang ada pada Instagram serta mengukur terpenuhinya konten yang mencapai KPI (Key Performance Indicator). Tanggapan dari para pengikut Instagram Mojok.co juga menjadi pertimbangan dari konten yang disajikan, misalnya melakukan pengamatan pada kolom komentar serta pesan yang masuk pada direct messages (DM) terkait kritik dan saran terhadap konten-konten Mojok.co.

\section{Perbaikan Pemasaran Konten (Content Marketing Improvement)}

Tahapan terakhir dalam pengelolaan content marketing adalah dengan adanya perbaikan peningkatan konten. Upaya peningkatan kualitas konten dilakukan dengan cara melakukan evaluasi secara berkala serta melakukan kurasi terhadap konten-konten yang ada, sehingga jika terdapat konten yang performanya tidak baik akan dicari penyebabnya, namun jika tidak ada perubahan akan dilakukan pergantian konten. Inovasi juga dilakukan Mojok.co dalam peningkatan kualitas konten. Tak hanya itu, Mojok.co juga selalu mengikuti perkembangan tren yang sedang ramai diperbincangkan di media sosial.

Penyusunan pesan pada content marketing Instagram Mojok.co dipertimbangkan agar konten yang disajikan tepat sasaran dan bermakna bagi pengikut Instagram Mojok.co. Pesan yang sering digunakan Mojok.co pada kontennya adalah pesan informatif dan pesan persuasif. Pesan informatif biasanya bersifat netral untuk beberapa isu sensitif yang dapat membuka diskusi dan opini dari pengikut akun Instagram Mojok.co.

Penyusunan pesan pada content marketing Instagram Mojok.co dipertimbangkan agar konten yang disajikan tepat sasaran dan bermakna bagi pengikut Instagram Mojok.co. Pesan yang sering digunakan Mojok.co pada kontennya adalah pesan informatif dan pesan persuasif. Achmad (1990) dalam Cangara (2014: 142) menjelaskan bahwa pesan yang bersifat informatif memiliki maksud sebagai sesuatu hal yang merupakan pengetahuan, di mana sebelumnya tidak diketahui oleh penerima. Pesan informatif biasanya bersifat netral untuk beberapa isu sensitif yang dapat membuka diskusi dan opini dari pengikut akun Instagram Mojok.co.

Pemaparan pesan dengan teknik persuasi yang digunakan pada konten Mojok.co yaitu pesan penuh emosi dan pesan humor. sesuai dengan cara yang dapat digunakan dalam penyusunan pesan (execution message) menurut Cangara (2014: 143) yaitu 1) pesan pesan yang penuh dengan emosi (emotional appeal), di mana pesan yang memiliki cara penyusunannya dengan berusaha menggugah emosi khalayak, misalnya dengan mengungkapkan masalah agama, etnis, kesenjangan ekonomi, diskriminasi dan semacamnya. Dalam hal ini, konten Mojok.co bersifat relateable, seperti konten dengan sajian yang menyenangkan, menghibur dan personal. Emosi lain juga dapat timbul akibat konten yang dapat menyinggung emosi pengikut Instagram Mojok.co. 2) pesan yang penuh humor (humorious appeal), di mana pesan dengan teknik penyusunan yang berusaha membawa khalayak tidak merasa jenuh. Pesan yang disertai humor mudah diterima dan menyegarkan. Dalam praktik penjualan banyak dilakukan dalam bentuk humor untuk menarik pelanggan. Konten Mojok.co juga berisi pesan bersifat sindiran 
terhadap isu yang sedang ramai diperbincangkan dan dikemas dengan gaya ringan atau humor khas Mojok.co.

\section{Aktivitas Brand Engagement pada Akun Media Sosial Instagram Mojok.co}

Pengelolaan content marketing Mojok.co berhubungan dengan aktivitas brand engagement yang dilakukan di Instagram selama ini dan seberapa pentingnya engagement bagi sebuah brand. Hal ini senada dengan pandangan Paine (2011: 79) bahwa terdapat tiga alasan utama mengapa engagement menjadi penting dalam media sosial. 1) engagement adalah langkah awal untuk membangun hubungan antara pelanggan dengan brand. Ini terlihat ketika admin media sosial Mojok.co berperan banyak dalam berinteraksi dengan para pengikutnya seperti menanggapi direct messages (DM) serta menanggapi komentar unik di kolom komentar dari konten yang disajikan. Komunikasi yang dilakukan Mojok.co juga dilakukan dengan gaya yang menyenangkan karena Mojok.co memposisikan diri sebagai range umur yang sama dengan pengikut Instagram Mojok.co. 2) engagement dengan pelanggan akan membantu dalam hal promosi serta dapat melindungi brand, yang pada akhirnya akan memunculkan brand advocates (pendukung merek). Ketika brand engagement meningkatsponsor iklan yang datang akan semakin banyak dan memiliki kepercayaan kepada Mojok.co. 3) engagement antara brand dan pelanggan akan membuat produk menjadi lebih baik. Jika kualitas konten yang disajikan Mojok.co baik dan sesuai, maka engagement yang didapat akan lebih baik pula. Hal ini membuat Mojok.co terus berusaha dalam pengembangan kualitas visual konten.

Brand engagement juga dapat dialami oleh pengikut Instagram Mojok.co, sehingga pengikut menjadi lebih dekat dan terlibat lebih dalam dengan Mojoko.co. Engagement antara brand dan pelanggan di media sosial Mojok.co hadir dalam beberapa fase atau tahapan yang senada dengan Paine (2011: 80-84) yaitu:

\section{Tahapan 1: Lurking}

Pada tingkat pertama engagement ini, hubungan sudah mulai terbentuk sejak pelanggan melihat sebuah konten dan memutuskan untuk menekan tombol "like" pada sebuah konten atau halaman akun media sosial. Pada tahapan awal, pengikut Instagram Mojok.co tertarik terhadap ilustrasi atau visual konten khas yang disajikan Mojok.co. Mereka beranggapan bahwa konten Mojok.co berbeda dengan media lain pada umumnya. Konten-konten Mojok.co hadir sebagai penyegar dan disajikan dengan bahasa yang ringan karena mengangkat isu atau fenomena dari hal-hal sepele namun menyenangkan.

\section{Tahapan 2: Casual}

Di tahap kedua ini, para pengikut Instagram Mojok.co sudah berada pada tahapan untuk mengikuti akun Instagram Mojok.co. Hal personal yang dialami para pengikut Mojok.co juga mulai dirasakan, seperti adanya perasaan tertarik terhadap konten-konten yang disuguhkan Mojok.co, hingga menemukan kebebasan berekspresi dalam berbahasa terkait hobi menulis yang dimiliki. Hal ini membuat para pengikut Instagram merasa dekat dengan Mojok.co. Senada dengan teori di tahap kedua ini yaitu ketika engagement benar-benar baru dimulai ketika pelanggan mengambil tindakan untuk melakukan kontak 
lebih lanjut. Misalnya berlangganan ke blog, mengikuti sebuah akun di Twitter atau Instagram, dan mengunduh video di YouTube.

\section{Tahapan 3: Active}

Dalam tahap ini, pengikut Instagram Mojok.co sudah berperan secara aktif, seperti mengikuti perkembangan konten atau artikel yang diunggah di Instagram Mojok.co, memberikan komentar di konten Mojok.co, hingga membagikan konten-konten Mojok.co kepada teman-teman mereka. Hal ini sesuai dengan teori pada tahapan ketiga ini di mana pelanggan tidak pernah merasa bosan dan selalu tertarik dengan konten pemasar di media sosial. Seorang pelanggan juga telah menemukan pelanggan lain yang berkumpul di dalam sebuah konten.

\section{Tahapan 4: Commited}

Dalam tahapan ini, pelanggan akan mengambil suatu tindakan, seperti bergabung lebih dalam lagi menjadi anggota pelanggan tetap dalam sebuah brand, mengirimkan e-mail ataupun bergabung mengikuti segala kegiatan yang diadakan oleh sebuah brand.

Para pengikut Instagram Mojok.co sudah memasuki tahap untuk berlangganan secara tetap di media sosial Instagram dan media sosial lainnya milik Mojok.co. Pengikut Instagram Mojok.co juga pernah mengikuti kegiatan atau acara yang diadakan Mojok.co di Yogyakarta serta bergabung lebih dalam lagi dengan brand Mojok.co, yaitu menjadi penulis Terminal Mojok dengan rutin mengirim tulisannya sendiri.

\section{Tahapan 5: Loyalist}

Pada tahapain ini saat pelanggan dapat terlihat kesetiaannya terhadap brand dengan cara seberapa sering pelanggan berkontribusi lebih dalam lagi ataupun mengajak banyak teman-temannya untuk bergabung menjadi pelanggan sebuah brand. Pengikut Instagram Mojok.co sudah dalam tahap keterlibatan lebih dalam dan menjadi pengikut setia. Aktivitas yang mereka lakukan adalah tidak hanya membagikan konten-konten Mojok.co, namun mengajak teman-teman mereka untuk mengikuti akun Instagram Mojok.co serta mengajak untuk mengirim tulisan ke Terminal Mojok.

Komunikasi pemasaran yang dilakukan Mojok.co dituturkan oleh salah satu tim media sosialnya (Ali Ma'ruf, 16 Juli 2020: wawancara personal) yaitu:

"Salah satu tujuan utama Instagram Mojok.co adalah untuk mendiseminasi tulisan dari web Mojok.co sebagai produk utama kami. Jadi kegiatan Instagram Mojok.co hanya sebatas memberi informasi, proses dan pembentukan citra."

Selanjutnya, adanya digital marketing yang dilakukan Mojok.co dipaparkan oleh admin media sosial Mojok.co (Dony Iswara. 20 Juli 2020: wawancara personal) di mana:

"Kegiatan digital marketing di akun Instagram Mojok.co lebih berfokus pada penyebaran konten (diseminasi), terutama lewat konten story, yang nantinya akan berpengaruh pada page views artikel di website Mojok.co." 
Selain itu, Mojok.co juga menerima adanya advertorial, menurut penuturan Ali Ma'ruf (2020) bahwa:

"Di Instagram Mojok.co kami menerima advertorial. Di beberapa advertorial yang kami tangani kami memakai beberapa pilihan format konten. Infografik, komik, dan konten multipost. Infografik biasanya lebih hardsale (menunjukkan produk dari awal) dari komik dan konten multipost yang menggunakan story telling dan membuat product placement lebih halus atau biasa kita sebut soft selling."

Dalam melakukan content marketing, Mojok.co juga mempertimbangkan konten yang dibuat. Hal ini disampaikan oleh ilustrator Mojok.co (Rean Aqila, 18 Juli 2020: wawancara personal) mengenai strategi pembuatan konten yaitu:

"Pertama, memodifikasi tokoh/fenomena/meme yang ikonik. Kedua, simplifikasi, pokoknya jangan dibikin ribet. Dua poin ini bisa diterapkan dengan menggabungkan dua hal jadi satu. Ketiga, kesan personal, yaitu udah jadi keseluruhan ilustrasi yang dibikin oleh ilustrator. Bukan dari freepick atau open source."

Pada pengelolaan content marketing, Mojok.co juga terus melakukan variasi konten seperti yang dituturkan oleh Rean Aqila (2020):

"Kalo sekarang lagi mencoba memperbanyak variasi konten, agar melebarkan jangkauan audiens. Ini kebantu banget dari \#HeadlineTerminal, karena sebelumnya konten Instagram cenderung didominasi dengan fenomena yang terjadi di lingkup Jogja dan Jawa aja. Nah dengan jumlah audiens yang meningkat diharapkan berdampak juga dengan peningkatan traffic. Traffic ini adalah segalanya untuk industri media haha karena traffic jugalah yang membuat sebuah brand mempertimbangkan untuk ngiklan hehe."

Target pasar Mojok.co dituturkan oleh Ali Ma'ruf (2020) yang didominasi oleh kalangan muda yaitu:

"Target pasarnya umur 18-24, pembaca Mojok.co rentang usia 25-34 sudah banyak, kami ingin menyasar pembaca baru dan orang-orang yang belum pernah membaca Mojok.co. Wanita diutamakan, sebab pembaca Mojok.co dari dulu selalu lebih banyak laki-lakinya. Kami ingin porsi pembaca kami seimbang. Untuk pendidikan, pekerjaan, dan tingkat penghasilan tidak terlalu kami permasalahkan."

Konten-konten yang ada pada Instagram Mojok.co dibagi menjadi dua konten utama. Hal ini dipaparkan oleh Dony Iswara (2020):

"Secara umum, konten feed di akun Instagram Mojok dibagi menjadi dua kategori. Kategori pertama adalah konten turunan. Konten turunan ini berupa screenshot headline artikel, baik artikel dari website Mojok.co maupun artikel dari Terminal Mojok. Tujuan dibagikannya konten screenshot headline artikel ini adalah agar audience terpancing untuk membaca artikel tersebut. Kategori konten kedua 
adalah konten orisinil. Yang dimaksud dengan konten orisinil adalah konten yang memang hanya diciptakan untuk akun Instagram Mojok.co dan tidak tersedia di website Mojok.co. Konten orisinil bisa berupa rekomendasi, komik, atau konten bertema starter pack. Pembuatan caption biasanya disesuaikan dengan jenis konten apa yang akan disebarkan (didiseminasikan). Jadi, caption sifatnya fleksibel, tergantung isi konten."

Mojok.co menggunakan owned media sebagai saluran distribusi konten seperti yang dipaparkan Ali Ma'ruf (2020):

"Kami owned media. Kami hanya memposting konten Instagram Mojok.co di Instagram Mojok.co. Dulu sempat ada anggaran beriklan untuk Instagram, iklannya mencakup Instagram $a d v$ dan facebook $a d v$. Tapi hal itu sudah tidak dilakukan lagi."

Dalam evaluasi content marketing, Mojok.co mempertimbangkan berbagai hal seperti yang dipaparkan oleh Rean Aqila (2020) yaitu:

"Biasanya kami akan eval konten medsos dalam jangka waktu tertentu. Tergantung dengan kebutuhan traffic yang tadi udah disinggung. Sebelum ada \#HeadlineTerminal dan Linktree kami belum mempertimbangkan pemasukan traffic dari Instagram. Jadi, kontennya cenderung suka-suka aja tapi tetep dievaluasi dari jumlah like dan engagement. Kalo dikit ya di-cut, atau diganti format. Kalo sekarang udah kurasi lagi mana yang bisa relateable dan shareable."

Ali Ma'ruf memaparkan mengenai aktivitas brand engagement yang dilakukan oleh Mojok.co yaitu:

"Yaaa kami berinteraksi secara aktif di $D M$ dalam membalas pertanyaanpertanyaan yang berkaitan dengan Mojok.co dan tidak menghiraukan di luar itu. Untuk kolom komentar kami juga merespons komentar yang unik dan menarik, tapi tidak selalu."

Mojok.co memiliki pengikut setia di Instagram-nya. Hal ini dipaparkan oleh salah satu pengikut Instagram Mojok.co (Muchamad Aly Reza, 28 Juli 2020: wawancara personal) saat pertama kali melihat konten Mojok.co:

"First impression pas tahu ada media kayak Mojok, apa ya? Kagum aja, sih. Dan mindset saya soal literasi yang selama ini saya pegang auto berubah. Pasalnya, kalau media-media lain pakai bahasa yang ndakik-ndakik dan terlalu tematis, Mojok menawarkan hal yang berbeda. Hal-hal receh, mind blowing, nyatanya bisa jadi konten. Dan maybe, itu dia daya tariknya. Karena nggak semua orang suka konten-konten (bacaan) berat dan filosofis, Mojok hadir sebagai penyegar."

Pengikut Instagram Mojok lainnya (Kiki Rezki Ananda, 24 Juli 2020: wawancara personal) memaparkan aktivitas yang dilakukannya selama menjadi pengikut Mojok.co: 
"Biasanya kalau ada postingan baru di Instagram Mojok, dan semisal itu bocoran artikel yang di upload, biasanya saya langsung cek artikel lengkapnya di portal Mojok. Tapi kalau isinya tentang infografis atau komik, terus relate sama saya dan kadang-kadang butuh pandangan temen lain juga, saya suka share ke Instagram Story atau misalnya habis baca artikel lengkapnya, saya juga share ke grup whatsapp atau via Direct Messages (DM). Dulu si yang biasa di share itu cukup banyak konten infografis atau komik sering menyentil anak kuliahan atau semester akhir. Kadang-kadang buat lucu-lucuan aja buat dikirim atau nge-tag temen-temen lain."

Kesetiaan pengikut Instagram Mojok.co terlihat dari pemaparan Kiki Rezki Ananda (2020):

"Saya mulai follow antara sejak 2014, 2015 atau 2016 gitu mba, aduh maaf saya lupa pas pertama follow Instagram Mojok. Sejak awal follow juga saya ga pernah ada niatan buat unfollow sih karena buat saya cukup informatif dan menarik. Mungkin kalau bergabung lebih dalam lagi gitu ya palingan saya udah follow semua akun Mojok di Twitter sama channel YouTube nya juga, soalnya bener-bener relate sama saya."

Muchamad Aly Reza (2020) juga memaparkan hal serupa yang sudah ia lakukan saat mengikuti Instagram Mojok.co:

"Kepikiran unfollow nggak ada sama sekali, sih. Saya menikmati Mojok, lumayan buat refresh pas lagi sumpek. Saya jadi pembaca Mojok udah hampir tiga tahunan, pernah ikut event bedah bukunya di Jogja. Terus baru bisa intens sebenernya malah baru awal tahun ini pas mulai berani nulis buat Terminal Mojok. Terminal Mojok kan ada grup WA-nya tuh, jadi ya kenal deket sama beberapa redaktur (utama) di Mojok."

Berdasarkan data penelitian dari wawancara peneliti dengan tim media sosial Mojok.co dan pengikut Instagram Mojok.co, berbagai hal telah ditemukan. Kegiatan komunikasi pemasaran dan digital marketing Mojok.co di Instagram lebih berfokus pada penyebaran (diseminasi) konten, serta membangun brand yang berpengaruh pada traffic web Mojok.co. Selain itu, dalam melakukan strategi content marketing, Mojok.co juga mempertimbangkan konten yang dibuatnya. Berbagai hal seperti melakukan variasi konten, memetakan target, hingga melakukan evaluasi konten juga dilakukan oleh Mojok.co dalam pengelolaan content marketing di Instagram.

Aktivitas brand engagement yang dilakukan Mojok.co berfokus pada interaksi yang dilakukan dengan para pengikut Instagram Mojok.co. Hal ini terlihat dari pihak Mojok.co yang menanggapi kolom komentar atau direct messages yang masuk ke Instagram Mojok.co yang dirasa penting serta menarik.

Pada sisi lain, brand engagement juga terjadi pada pengikut Instagram Mojok.co. Hal pertama yang dirasakan yaitu adanya rasa ketertarikan saat pertama kali melihat kontenkonten Instagram Mojok.co yang bersifat relateable. Rasa ketertarikan terus berlanjut hingga para pengikut ingin mengikuti akun Instagram Mojok.co dan membagikan konten Mojok.co kepada teman-teman mereka. Tak hanya itu, pengikut Instagram Mojok.co juga 
bergabung lebih dalam lagi di Mojok.co, seperti menjadi penulis di Terminal Mojok dan mengikuti acara yang pernah digelar oleh Mojok.co.

\section{Simpulan}

Berdasarkan hasil penelitian dan pembahasan mengenai strategi digital content marketing di akun media sosial Instagram Mojok.co dalam mempertahankan brand engagement, dapat ditarik kesimpulan bahwa strategi content marketing di Instagram Mojok.co lebih mengutamakan pembuatan konten yang dapat memancing engagement, jangkauan, audiens dan ilustrasi konten ala Mojok.co.

Selanjutnya, dalam pengelolaan content marketing di Instagram, Mojok.co melakukan berbagai tahapan dan 9 langkah, yaitu menetapkan Tujuan (Goal Setting), terkait brand, memetakan Target Pasar (Audience Mapping), menggagas dan merencanakan konten (Content Ideation and Planning), menciptakan konten (Content Ideation), mendistribusikan konten (Content Distribution), menguatkan konten (Content Amplification), mengevaluasi pemasaran konten (Content Marketing Evaluation), memperbaiki pemasaran konten (Content Marketing Improvement), mengelola content marketing untuk brand engagement.

Pengelolaan content marketing berhubungan dengan adanya aktivitas brand engagement. Aktivitas brand engagement dilakukan oleh admin media sosial Instagram Mojok.co yaitu berinteraksi dengan para pengikut Instagram, adanya pengukuran variabel konten Mojok.co seperti impresi dan engagement, serta peningkatan kualitas konten agar engagement yang didapat baik pula. Brand engegement juga dialami oleh pengikut Instagram Mojok.co melalui beberapa 5 fase atau tahapan yaitu: 1) Lurking, pada tahap awal, pengikut Instagram Mojok.co tertarik terhadap ilustrasi atau visual konten khas yang disajikan Mojok.co. Konten Mojok.co berbeda dari media lain pada umumnya karena konten yang disajikan hadir sebagai penyegar dengan bahasa yang ringan dan bersifat relateable; 2) Casual, pengikut Instagram Mojok.co sudah berada pada tahapan untuk mengikuti akun Instagram Mojok.co. Hal-hal personal lain mulai dirasakan, seperti adanya perasaan tertarik terhadap konten-konten Mojok.co hingga menemukan kebebasan berekspresi; 3) Active, Dalam tahapan ini, pengikut Instagram Mojok.co sudah berperan secara aktif, yaitu dengan mengikuti perkembangan konten atau artikel di website Mojok.co, memberikan komentar diunggahan konten, hingga membagikan konten kepada teman-teman mereka; 4) Commited, pada tahap ini, pengikut Instagram Mojok.co sudah berlangganan secara tetap di media sosial Instagram dan media sosial lainnya milik Mojok.co, mengikuti kegiatan atau acara yang diadakan Mojok.co serta bergabung menjadi penulis Terminal Mojok; 5) Loyalist, pada tahap terakhir ini, pengikut Instagram Mojok.co sudah terlibat lebih dalam lagi dan menjadi pengikut setia. Aktivitas yang sering dilakukan pada tahapan ini adalah lebih sering lagi untuk mengajak teman-teman mereka untuk mengikuti akun Instagram Mojok.co dan mengirim tulisan ke Terminal Mojok.

Dari hasil penelitian ini, untuk peneliti selanjutnya diharapkan meneliti lebih dalam terkait strategi content marketing yang dilakukan Mojok.co, misalnya dengan melakukan observasi lapangan di mana terlihat jelas proses dalam melakukan pengelolaan content marketing secara langsung. 


\section{Daftar Pustaka}

Buckingham I (2008) Brand engagement. London: Palgrave Macmillan.

Cangara H (2014) Perencanaan dan strategi komunikasi. Jakarta: Rajawali Pers.

Chakti GA (2019) The book of digital marketing. Makassar: Celebes Media Perkasa.

Djamal (2017) Paradigma penelitian kualitatif. Yogyakarta: Mitra Pustaka.

Kapoor A (2011) Branding and sustainable competitive advantage: building virtual presence: building virtual presence. Pennsylvania: IGI Global.

Kotler P, Kartajaya H \& Setiawan I (2017) Marketing 4.0: moving from traditional to digital. Amerika Serikat: John Wiley \& Sons.

Pandrianto N \& Sukendro GG (2018) Analisis strategi pesan content marketing untuk mempertahankan brand engagement. Jurnal Komunikasi, 10: 167-176.

Prasetyo BD, Febriani NS, Asmara WW, Tamitianini DD, Destrity NA, Avina DAA, Illahi AK (2018) Komunikasi pemasaran terpadu: pendekatan tradisional hingga era media baru. Malang: UB Press.

Sanawir B \& Iqbal M (2018) Kewirausahaan. Malang: UB Press.

Setiawan I \& Savitry Y (2016) New content marketing. Jakarta: Gramedia Pustaka Utama.

Tim Website (2019) Data Profil Mojok.co [Diakses pada tanggal 13 Desember 2019] https://mojok.co/tentang/.

Tim Website (2020) Data Brand Engagement Situs Web Mojok.co [Diakses pada tanggal 23 Januari 2020] https://gardamaya.com/our-works/situsweb-mojok/.

Tim Website (2020) Data Penelitian Efektivitas Content Marketing di Sektor B2B Organisasi [Diakses pada tanggal 13 Desember 2019] https://academy.getcraft.com/id/blog/efektivitas-content-marketing. 